Olivera RASHIKJ-CANEVSKA

UDK: 364.622-53-053.2

Original research paper

\title{
THE IMPACT OF HOSPITALIZATION ON PSYCHOPHYSICAL DEVELOPMENT AND EVERYDAY ACTIVITIES IN CHILDREN
}

\begin{abstract}
Hospitalization plays an important role in the care for children's health, especially children that require intensive medical care. In comparison to adults, as a result of the insufficient emotional and cognitive maturation on the one hand and the lack of sufficient and appropriate information on the other side, children are significantly more influenced by hospitalization and its associated factors. In addition to having to face the normal developmental lawfulness, hospitalized children also have to face the challenges of separation from their home and family, hospitalization, illnesses and clinical procedures that they will undertake.

The intensity and the type of the psychosocial reaction of children to the hospitalization depends on significant variables such as the child's age, gender, personality traits, type and severity of the illness, type of treatment, duration of the inpatient length of stay and the time organization in the hospital. The hospitalization usually has a negative impact on the motor, cognitive, emotional and social development of the child.

Most negative experiences of hospitalization are due to poor attention to the developmental needs of children in health care planning in hospitals and bad organization of the leisure time.
\end{abstract}

Key words: HOSPITALIZATION, PSYCHOPHYSICAL DEVELOPMENT, NEGATIVE EFFECTS, PLAY, EDUCATION

\section{Introduction}

The focus of my research is on the question: How does long-term hospitalization impact the psychophysical development of a child and the performance of its daily activities?

The illness is a major stressor in one's life. Various symptoms of the illness put the body into a state of continuous tension, cause fatigue, low mobility or immobility and even loss of bodily functions and control (Rowe, 1996). In addition to the illness, the hospitalization by itself can cause a wide range of short-term as well as long-term consequences.

The modern hospital centres are geared towards providing a safe and healing environment for children afflicted with a variety of illnesses and conditions. Patients 
receive the most contemporary care available, they have dedicated doctors and benefit from the modern technology progress in the medicine science (Rollins, 2004). But still, experiencing an illness and hospitalization nonetheless exert a great deal of psychological distress, one of the most distressful events people might actually experience in their life time. When being admitted to the hospital, a serious disruption in one's life occurs, as well as in one's daily routines and activities. An admission to the hospital means being separated from home, from one's family and known surrounding, experiencing a change in the daily functioning and going through a series of unpleasant experiences opposite to the need of the child's development (Gerali et al., 2011). The stressful influence of hospitalization is further increased due to frequent restrictions of the activities and dependence on others, indirectly leading to feelings of vulnerability, and developmental problems (CDC, 2013).

\section{How children perceive illnesses and what the effects of hospitalization are accord- ing to the age and gender}

When comparing new-borns to adolescents, hospitalization has varying longterm developmental effects, and children between 6 months and 4 years of age are at a greater risk than older children (Emde \& Harmon, 1984). Between age one through five, hospitalized children tend to go through stages of anxiety due to separation from their parents and loved ones. Children that are under the age of three are the most vulnerable to the possible effects of prolonged hospitalization. Their increased susceptibility is based on Freud's theories of psychosexual development, pointing out that for a three year old child, "separation from the mother...is often misinterpreted as punishment, because they are an integral part of a system, of a biological unit, formed by them and their mothers. As the stages of separation anxiety progress, a child tends to "regress" and will also have a difficult time re-adjusting and reattaching (Freiberg, 1972). Between the age of two and a half and five years the child's capacity to tolerate short-time separations from his mother increases markedly.

As children grow up and mature, their thinking with regard to illnesses starts to become similar to the one of the adults and their environment, but initially, parental ideas about illnesses do not match the ideas held by the child. Koopman, et al. (2004), point out the Piaget's model as a way of developing the child's view of the illness.

- "Invisible" phase: Children in this stage tend to create associations rather than understanding the major characteristics of a chronic condition and they do not consider the "What? Why?...How? aspects of the illness."

- "Distance" phase: is defined as a stage where children are unable to make a connection between the body and the illness. 
- "Proximity" phase: is when children understand the illness as being related to their immediate surroundings and that falling ill is a result of "contamination by nearness."

- "Contact" phase: characterized by a widening definition of the disease and an increased comprehension of the causes of the disease. Children are still unable to differentiate between the roles that the mind and body can play in an illness, but there is an understanding of the fact that medicine can cure an illness.

- "Internalization" phase: development of a basic awareness that the cause of a disorder can be found in the body, and the cause for an illness can be due to external factors or health-affecting behaveours.

There are also studies about different reactions according to the gender of the children. Small et al. (2009) in their research defined internalizing, externalizing, and post hospital behaviours as comparison criteria. Boys tend to exhibit more of the externalizing behaviours than girls do (argues when denied his own way, hits other children, talks back to parents, orders other around, interrupts parents when they are talking, screams, blames others), boys' behaviours peaked earlier and declined in a shorter amount of time. Girls more often exhibit internalizing behaviour (described as worries about things that cannot be changed, worries, complains of pain, are afraid of dying etc.), and the externalizing behaviours that females did demonstrate seemed to start later and persist for an extended period of time.

\section{Negative influences of hospitalization on the psychophysical development of chil-} dren

The reaction of children on their retention and treatment in the hospital is individual and as it was stated above it depends on different interrelated factors. Over the past 20 years many studies have been conducted to determinate the child's developmental effects of hospitalization, and it was found that $30 \%$ of hospitalized children manifested a variety of behavioural changes which were not present before the hospitalization.

The literature review indicates that the most common consequences of hospitalization are: regressive behaviour, increased dependence and occurrence of pathological dependence, loss of bowel sphincters control and occurrence of enuresis nocturne, often phobias (fears of hospitals, darkness, strangers) sleeping and eating disorders, ticks, tantrums, negativism.

The hospitalized children's level of physical activities is inherently limited, environment stimulations and peer relations are minimalized, which could pose a risk for making a wrong sense of the world around them, social deprivation and occurrence of pseudo retardation, or insufficient exploitation of developmental capacities (Hiat, 
Bar-Mor, Shochat, 2003). Limited opportunities for movement and exploration on the one hand and the illness or surgery on the other hand often lead to poor body image and movement coordination. Due to the factors that cause isolation and poor body image, children that are diagnosed with a severe illness at a young age tend to develop depressive and anxiety disorders. Curtis and Luby (2008) in their study noted that, "as many as $4 \%$ to $14 \%$ of school-aged children exhibit depressive symptoms within three months after the diagnosis of a medical illness, while patients of three years of age experienced depressive symptoms such as sadness, irritability, whining, crying, and selfblame, and so on.

In our study conducted in the "University clinic for pediatric diseases" and the "Children hospital - Kozle" including 30 children aged 3-7 years and 30 parents, we have determined that $80 \%$ of children feel lonely and want more often to be near their parents, $57 \%$ of them sometimes feel sad and 53\% feel angry. One half of the children have decreased interest in the activities that take place in their school or kindergarten, and $47 \%$ of children do not express feelings ${ }^{1}$.

A number of studies conducted in pediatric hospitals pointed that hospitalized children tend to engage in less play activities, and when they do engage, their play is characterized by repetitive, solitary themes. This is unfortunate and even damaging as play represents a basic mechanism for overcoming fear and facing stressful situations in children.

Our findings indicate that $93 \%$ of children spend most of their free time playing games on IT devices, $90 \%$ of children listen to music, $87 \%$ play cards with their parents, $57 \%$ read books.

Another type of problem that occurs after a long hospitalization is a transition back into "normalcy". Low self-esteem, a poor body image and the feeling of isolation present an obstacle to school continuation and participation in social events (Geist et al., 2003).

\section{How to reduce the negative effects of hospitalization}

During a child's period of hospitalization, all members of the hospital staff included in the child's treatment and care should be able to prevent or decrease the psychosocial impact of hospitalization on ill children. The very first step in the prevention is preparing the children for hospitalization. A lot of world hospitals have developed preparatory programs for children hospitalization, involving physicians, nurses, psychologists, social workers, special educators and occupational therapists, and the programs consists of several steps (Gonzalez-Gil et al., 2008):

\footnotetext{
${ }^{1}$ Research conducted as part of the graduate thesis "The impact of the hospitalization on the everyday activities in children" prepared by the candidate Ana Tasevska mentored by assistant prof. Olivera Rashikj-Canevska, at the Institute of Special education and rehabilitation
} 
1. Informing the child about the stay in the hospital, the way of functioning, the procedures and treatments, the visit hours etc.;

2. Adjustment time. The child usually needs time to understand the information that was given and to adapt to the new situation, and the period of adaptation lasts 5-8 days when the child asks many questions and needs a precise answers.

3. A short visit to the hospitals previous to the hospitalization, in order to get to know the hospital.

4. To be allowed to take some object from home to the hospital.

Parents and the extended family play an important role in reducing the psychosocial influences of hospitalization, so in this direction preparations for the parents themselves and for the siblings are necessary.

In addition to the preparations made before the admission of the child in the hospital, modern hospitals have also developed recreational programs adapted to children of different ages and with different abilities. The recreational programs aim to help the child to control the newly emerged situation and to get used to hospital conditions and treatments, to preoccupy their thoughts and to improve their psycho-physical condition (Рашиќ-Цаневска, 2016). Some hospitals have hired hospital clowns for children animation, and a hospital in Toronto, Canada has opened a theatre for children in order to help them face their fears (Rokach, Matalon, 2007).

When it comes to school aged children that stay in hospital for longer than 15 days, there should be organized education from their schools or the schools near the hospitals, which will provide continuity of the educational process, easier child integration into the hospital, reducing loneliness and fear, creating conditions for their returning to school. Teaching is according to an adapted curriculum, children are monitored, results are recorded, but the final assessments and scoring are done after the returning to school.

From the data of our research we can notice that children in our hospital are not included in any program activities, there is no teaching, voluntary workshops supported by the city of Skopje are organized 2-3 times per year. Regarding information and preparedness, $93 \%$ of parents need additional information about their child's condition, $60 \%$ do not know how to help the child in certain situations when they feel pain or fear, $83 \%$ need more information to learn how to help their child during the treatment and rehabilitation.

\section{Conclusion}

From the literature analysis and from the results of our research it can be concluded that hospitalization leaves a trace in the life of every child who stays in a hospital for a long time. In order to reduce the negative effects, it is necessary to pre-prepare the child and his family and organize their time in the hospital, giving the child the opportunity to have time to play, which is the basic mechanism for the development of the child as well for facing stressful situations and life challenges. 


\section{References}

Centers for Disease Control and Prevention (CDC). (2013). Faststats: Child Health. Available at. http://apps.nccd.cdc.gov/uscs/ChildhoodCancerData.aspx, Accessed on May 2, 2013.

Curtis, C. E., \& Luby, J. L. (2008). Depression and social functioning in preschool children with chronic medical conditions. The Journal of Pediatrics, 153(3), 408-413.

Freiberg, K. H. (1972). How parents react when their child is hospitalized. The American Journal of Nursing, 72(7), 1270-1272.

Gariépy N., Howe N. (2003). The therapeutic power of play: examining the play of young children with leukaemia. Child Care Health Dev 29: 523-537. [Crossref]

Geist, R., Grdisa, V., \& Otley, A. (2003). Psychosocial issues in the child with chronic conditions. Best Practice \& Research Clinical Gastroenterology, 17(2), 141-152.

Gonzalez-Gil F., Jenaro C., Gomez-Vela M, Flores N. (2008). Perceived quality of life and health of hospitalized children. Child Indicators Research 1: 198-220.

Haiat H, Bar-Mor G, Shochat M. (2003). The world of the child: a world of play even in the hospital. J Pediatr Nurs 18: 209-214. [Crossref]

Hughes B. M. (2001). Psychology, hospitalization and some thoughts on medical training. European Journal of Psychotherapy and Counselling, 4: 7-26.

Koopman, H. M., Baars, R. M., Chaplin, J., \& Zwinderman, K. H. (2004). Illness through the eyes of the child: the development of children's understanding of the causes of illness. Patient Education and Counseling, 55, 363-370.

Maria Gerali, Marina Servitzoglou, Dimitra Paikopoulou, Helen Theodosopoulou, Michael Madianos, Helen Vasilatou-Kosmidis. (2011). Psychological Problems in Children with Cancer in the Initial Period of Treatment Cancer Nurs.; 34(4):269-276.

Robert N. Emde, Robert J. Harmon. (1984). Continuities and Discontinuities in Development. New York and London: Plenum press.

Rokach A, Matalon R (2007) 'Tails' - A fairy tale on furry tails: A 15-year theatre experience for hospitalized children created by health professionals. Paediatr Child Health 12: 301-304. [Crossref]

Rollins JA (2004) Evidence-based hospital design improves health care outcomes for patients, families, and staff. Pediatr Nurs 30: 338-339. [Crossref]

Rowe MA (1996) The impact of internal and external resources on functional outcomes in chronic illness. Res Nurs Health 19: 485-497. [Crossref]

Small, L., Melnyk, B. M., \& Sidora-Arcoleo, K. (2009). The effects of gender on the coping outcomes of young children following an unanticipated critical care hospitalization. Journal for Specialists in Pediatric Nursing, 14(2), 112-122.

Рашиќ-Цаневска, Оливера. (2016). Окуйациона йерайија. Скопје: Филозофски факултет. 